um defeito e vem a ser - estar no inteira dependência do presidente e portanto precário para quem tem uma opinião política. Eu desejava ver-te juiz de direito, mas enfim, creio que não irás caminho errado se aceitares a nomeação de inspetor. Torno a repetir - como lugar de influência politica é excelente".

Outro detalhe sintomático, que aparece ilustrado em vários lugares, é o da questão da nomeação do presidente da província e a problemática dos interesses locais: como se sabe, a nomeação era feita pelo Imperador, e o comum era que o indicado não estivesse ao par dos problemas específicos da província, nem do equilibrio de forças existentes. Daí o envolvimento, às vezes prejudicial, que sofria o recém-nomeado presidente da província, e a política particularista adotada nesta circunstância. Quando trata da nomeação do Barão de Vila da Barra para presidência da Província do Rio de Janeiro (1876), Lafayette torna claro esta condição, quando diz que o barão é "excelente homem, mas estranho à chicana política e portanto fácil de ser enganado".

As eleições é que aparecem como exemplo de jogos de interesses mais complexos. A política pessoal sobrepassa à partidária, 0 que leva os entendimentos e acordos a serem rompidos com facilidade, como aparece em vários momentos do livro. Candidato por Minas Gerais, nas eleiçōes de 1876, Lafayette fizera a campanha eleitoral, certo do apoio dos seus correligionários do Partido Liberal; escreve " 800 cartas para todos os colégios da próvíncia". Mas, os resultados das eleições são negativos, pois, "até ontem, - resultado da apuração dos colégios conhecidos me era favorável; mas hoje o resultado do colégio de Sabará e Santa Luzia desequilibrou-me completamente. E uma traição indigna de Assis Martins. Temendo ser "cortado no Serro, Diamantina e São João Batista, onde os católicos não filaram um só voto, o J. Martins sacrificou-me e ao Afonso Pena para dar votos ao Mariz Águia... chefe dos católicos do Serro. Mas há de pagar caro essa indignidade. Eu, Pena e Prados (igualmente traido) nos ligaremos na primeira oportunidade. Além disso, o Lobo por sua parte the tomará conta". Em ou- tra carta diz ainda espérançoso: "o antigo 2. ${ }^{\circ}$ distrito me tem sido terrivelmente hostil. Em Santa Luzia só tive 5 votos, em Sabará 13, em Sete Lagoas 7 e agora no Pará 1. Acredito que nisto andou dedo de J. Martins, porque por toda a província os liberais receberam bem o meu nome".

O Conselheiro Lafayette é um dos signatários do famoso Manifesto Republicano de 1870, que abre perspectivas novas no movimento político brasileiro. $\mathrm{Na}$ correspondência não aparece 0 mínimo índice de suas gtitudes republicanas, somente sendo assinalada, numa única nota, a existência do manifesto do Centro Liberal (1868).

Seu casamento mostra, por sua vez, a problemática social da mulher $e$ as condiçōes institucionais vigorantes, aparecendo claramente a ligação entre contrato de casamento e dote, traço comum na sociedade européia da época. "Estou de casamento justo com a Exma. Sra. D. Francisca Coutinho, menina de dezenove anos de idade, formosa como um anjo caído do céu, de uma educação primorosa, modesta, singela, inteligente, amiga da economia, de costumes puríssimos e habituada a viver longe do bulício do mundo... E filha legítima do Dr. José Júlio de Freitas Coutinho, antigo advogado nesta corte e sogro de Silveira Martins. É uma moça tal como eu sempre imaginara para minha mulher, boa, santa $e$ capaz de viver de pouco. E a filha mais moça e herdeira da terça parte do pai".

Os dados sobre os infortúnios da jovem República, a sua atuação durante a Missão ao Chile, e as notas relativas ao Gabinete dirigido por ele (1883) completam o ciclo de informações desta correspondência inédita, publicada atualmente.

Edgard Carone

\section{Lembranças do Brasil}

Por Pedro Ludwig e William Briggs. Introdução por Lygia da Fonseca Fernandes da Cunha. Rio de Janeiro, Sedegra, s/d.

A reedição do álbum de litografia de Ludwig e Briggs permite-nos entrar novamente em contato com uma das fontes artísticas e históricas fundamentais do nosso passado. As estampas, em número de 30 , fazem parte de um conjunto denominado The Brazilian Souvenir: a selection of the most peculiar costumes of the Brazils e realizadas entre $1846 \mathrm{e}$ 1849.

A sociedade Ludwig e Briggs concretiza-se em 1843. Como grande número de outros artistas estrangeiros, William Briggs e Pedro Ludwig instalam sua própria oficina esperando "poder servir aquelas pessoas que o honrarem, com presteza e perfeiçõo em tudo que diz respeito a litografia, como desenhos, mapas, cartas topográficas, planos de arquitetura, emblemas, diplomas, vinhetas, circulares, faturas, letras de câmbio, etc., assim como quaisquer trabalhos, por mais delicados que sejam, afiançandose serem perfeitamente gravados, e iguais às melhores obras que se fazem na Europa".

O oficina também aproveita-se da obra de artistas nacionais ou que se encontram de passagem pelo Brasil. As aquarelas originais, que serviram de base às cópias litográficas de Ludwig e Briggs, são de autoria do artista alemão Edward Hildebrandt. Este aporta ao Rio em 1844 e de sua passagem por esta cidade, Salvador, Recife e São Paulo conhece 
170 aquarelas, onde "vistas e costumes se sucedem, fixados com excelente técnica e apuro de cores. Nelas encontramos tipos e flagrantes populares que podem ser identificados no álbum Brazilian Souvenirs onde, copiados pelos litógrafos, perderam um pouco da espontaneidade devida a seu talento criador".

As 30 litografias dão, no entanto, um excelente apanhado de costumes e tipos imperiais: Aí aparecem retratados o mascate, um frade, uma rede, guardas nacionais, ama-de-leite, carroça d'água, castigos contra pretos, quitandeira de galinhas, um mineiro, carro da alfândega, tropeiros, enterro de anjinho, dança de negros, família indo à missa, carregadores de café, lavadeiras, festa do Espírito Santo, cadeirinha, pedindo esmolas, negra baiana, um padre, etc.

As litografias realçam sempre o tema visado, expondo-o em primeiro plano. Para isso, o primeiro plano sempre aparece em cores, enquanto o fundo é em branco e preto. São "verdadeiros instantâneos, primando alguns pela naturalidade, como por exemplo: as lavadeiras num arrebalde à beira do rio lavam e estendem a roupa branca; o mineiro que parece ter-se apeado do cavalo naquele instante, sobe a rampa, enquanto - senhor voltando a cabeça o interroga sobre os acontecimentos na sua ausência; o membro da irmandade, paramentado com a opa colorida, segura pela mão, com todo o cuidado, a menina vestida de anjo para que não suje - pezinho calçado com o sapato de cetim de igual cor do vestido", etc.

No entanto, permanece presente a "preocupação de ligar o assunto principal, isto é, o tipo a ser documentado a um detalhe sugestivo que o entrose no ambiente; assim, as quitandeiras têm por fundo um toldo armado no mercado e cestas espalhadas em torno da figura; os religiosos e pedintes, os irmãos das sociedades religiosas ressaltam dos esboços de portais barrocos ou igrejas de fachadas mais rígidas; - mascate passeia em ruas de arrabalde, caracterizadas pela arquitetura tradicional; os carregadores de café têm por fundo os muros de alfândega, e assim por diante.
A riqueza dos elementos e a técnica artística fazem deste documentário obra de valor inestimável para a nossa história da arte e de costumes. Porém, esperamos que se publiquem outras obras raras do nosso passado, que continuam a ser de difícil manuseio, pois elas existem somente nas mãos de raros colecionadores de brasilianas ou em algumas bibliotecas públicas.

Edgard Carone

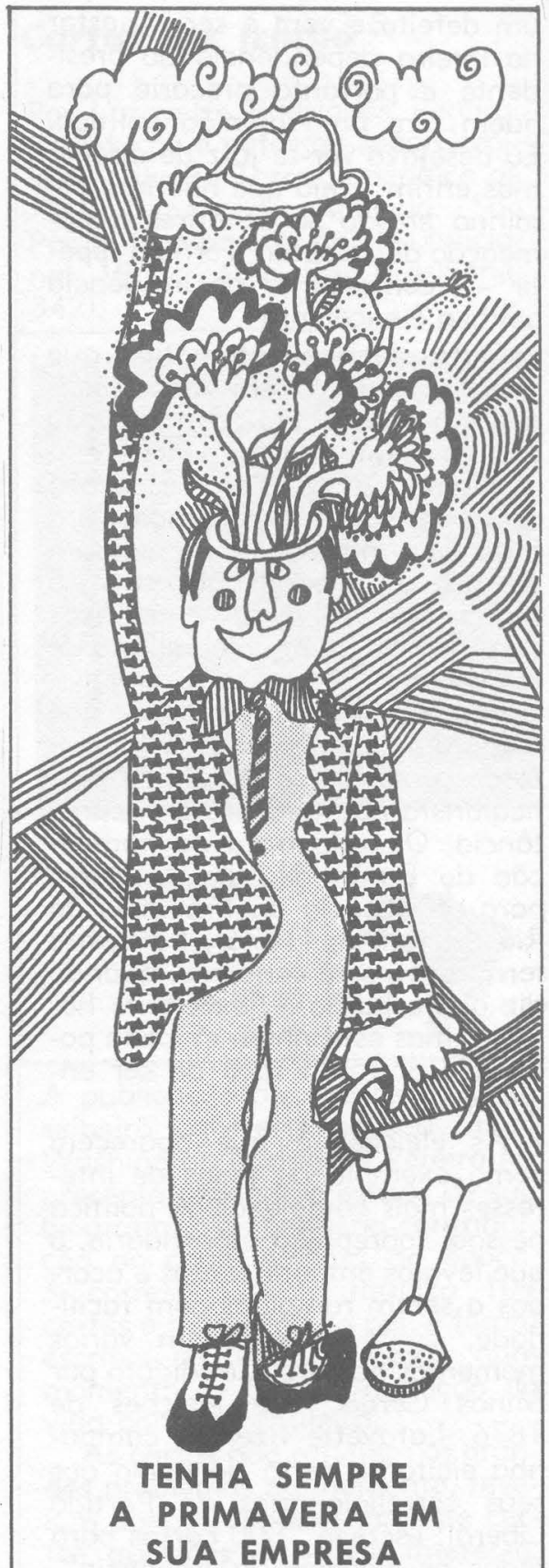

Já se foi o tempo em que as decisões empresariais comportavam riscos e tensões. 0 empresário vivia em clima de aventura, arriscando em cada lance seu tempo, seu capital, sua tranquilidade. E precisava do chamado pulso firme para suportar os reveses.

Tristes tempos.

Hoje, graças aos métodos modernos de administração, tudo vai mais tranquilo. Sem intemperies. Uma só primavera. A estação que dura 0 ano inteiro para os leitores da Revista de Administração de Empresas.

Leia a RAE. Mantenha a primavera em sua empresa. 